\title{
FBXO32, a new TGF- $\beta /$ Smad signaling pathway target gene, is epigenetically inactivated in gastric cardia adenocarcinoma
}

\author{
W. GUO, M. ZHANG, Y. GUO, S. SHEN, X. GUO, Z. DONG* \\ Laboratory of Pathology, Hebei Cancer Institute, the Fourth Hospital of Hebei Medical University, Shijiazhuang, Hebei, China \\ *Correspondence: dongzhiming2000@163.com
}

Received December 1, 2014 / Accepted March 4, 2015

\begin{abstract}
FBXO32 has recently been identified as a TGF- $\beta /$ Smad signaling pathway target gene, involved in regulating cell survival and may be transcriptionally silenced by epigenetic mechanisms in some kind of carcinomas. The present study was to investigate the role and promoter methylation status of FBXO32 in gastric cardia adenocarcinoma (GCA), and determine the prognostic significance of FBXO32 in GCA. Bisulfite Conversion-Specific and Methylation-Specific PCR, real-time RTPCR and immunohistochemical staining methods were used to detect the methylation status and expression of FBXO32 in GCA samples. The frequency of FBXO32 methylation in GCA tumor tissues (44.6\%) was significantly higher than that in corresponding normal tissues (3.6\%) and was associated with TNM stage, pathological differentiation, distant metastasis or recurrence and upper gastrointestinal cancers (UGIC) family history. Decreased mRNA and protein expression of FBXO32 was observed in GCA tumor tissues and was associated with FBXO32 promoter methylation status. A positive correlation between FBXO32 and p-Smad2/3, Smad4 protein expression was also found in clinical specimens. GCA patients in stage III and IV, with positive UGIC family history, and hypermethylation and down-expression of FBXO32 were most likely to develop metastatic disease and also showed the worse survival. In all, aberrant hypermethylation of FBXO32 may be one of the mechanisms that lead to loss or down expression of the gene in GCA, FBXO32 may be a functional tumor suppressor and reactivation of FBXO32 gene may has therapeutic potential and may be used as a prognostic marker for GCA patients.
\end{abstract}

Key words: FBXO32, methylation, expression, gastric cardia adenocarcinoma

Due to the improvement in early endoscopic screening and pathologic diagnosis, gastric cardia adenocarcinoma (GCA), which was formerly considered as gastric cancer or esophageal cancer, has been diagnosed independently in very recent years. During the past two decades, epidemiological studies have shown a continuously increased trend in incidence and mortality of GCA but a steady decline in incidence of noncardia gastric cancer, thus emphasizing the importance of pathogenesis and prevention research of GCA [1]. In China, based on two national mortality surveys conducted in 1970s and 1990s, there is an obvious regional aggregation distribution of gastric cancer in the country, with the high mortality being mostly located in rural areas, especially in Hebei, Shanxi, Henan, and Gansu Provinces [2, 3]. A variable proportion of GCA cases strongly point to upper gastrointestinal cancers (UGIC) family history especially in the high incidence regions [4]. The exact mechanisms of the occurrence of GCA still remain unclear for the moment. Exogenous factors including consumption of alcohol and tobacco, unhealthy living habits, nutrition deficiency, and pathogenic infections are generally considered as the risk factors for developing GCA in China [5, 6], however, only a part of individuals exposed to the above listed exogenous risk factors would develop GCA, suggesting that multiple genetic and epigenetic events may contribute to the occurrence and progression of GCA.

FBXO32 (also known as atrogin-1) is a member of the Fbox protein family and constitutes one of the four subunits of the ubiquitin protein ligase complex involved in muscle atrophy $[7,8]$. FBXO32 is very strongly induced in many catabolic states and play an important role in the generation of muscle atrophy. The inductions of FBXO32 expression at an early stage of muscle wasting, and the maintenance of its high expression during the period when overall proteolysis is accelerated, strongly indicate the key role of FBXO32 in initiation and maintenance of the accelerated proteolysis [9]. However, recent findings demonstrated that FBXO32 
may be involved in regulating cell survival and may be act as a potential tumor suppressor $[10,11]$. Recently, Qin et al. identified FBXO32 as a TGF- $\beta /$ Smad signaling pathway target gene in ovarian surface epithelial cell using chromatin immunoprecipitation microarray method [12]. Transforming growth factor- $\beta$ (TGF- $\beta$ ) signaling pathway plays important role in the regulation of numerous effects on cell proliferation, differentiation, migration, and survival that affect multiple biological processes, including carcinogenesis, wound healing, fibrosis, and immune responses [13]. TGF- $\beta$ initiate its signal transduction cascade by binding to trans-membrane receptor type I and II (TGFBR1 and TGFBR2), which form an oligomeric complex and then transmit the signal into the cell via phosphorylation of $\operatorname{Smad} 2 / 3$ proteins. Phosphorylated Smad2/3 forms dimers or trimers with another protein, Smad4, and this resultant Smad complex is then translocated to the nucleus where it interacts with other DNA binding co-regulators to modulate the transcription of TGF- $\beta / \mathrm{Smad}$ target genes [14]. The abnormal signal transduction of TGF- $\beta$ signaling pathway is well known for its contribution to occurrence and progression of different kinds of tumors [15].

In our previous study, we have found decreased protein expression of TGFBR1, TGFBR2 and Smad4 was closely associated with increased expression of TGF- $\beta 1$ in GCA. The hypermethylation of TGFBR1 and TGFBR2 in GCA tissues was significantly correlated with decreased mRNA and protein expression of both genes [16]. It is generally considered that epigenetic modifications, including DNA methylation and histone modifications play important roles in regulating gene transcription [17]. DNA methylation which occurs at the cytosine residues is one of the most common mechanisms in controlling epigenetic silencing in mammalian cell [18]. Our and other authors studies have previously shown that tumor suppressor genes can be transcriptionally silenced by epigenetic alterations in GCA and epigenetically modified genes may be useful for both GCA diagnosis and prognosis [19-21]. More recently, FBXO32 has been shown to be transcriptionally silenced by epigenetic mechanisms in MCF-7 breast cancer cells and a series of ovarian cancer cell lines [11,22]. Chou et al. also found promoter hypermethylation of FBXO32 in ovarian cancer cells and the methylation status of FBXO32 may predict the survival of ovarian cancer patients [22]. Even with the potential importance of FBXO32 gene in carcinogenesis, little has been investigated about the role of FBXO32 gene in GCA. In the present study, we detected the expression and methylation status of FBXO32 in GCA and further evaluated the role of FBXO32 in GCA patients' prognosis, in order to provide more information on the role of FBXO32 with regard to the pathogenesis of GCA.

\section{Patients and methods}

Patients and specimens. All study subjects were ethnically homogeneous Han nationality and permanent residents of Hebei province and its surrounding regions which include high incidence regions of GCA. Tumor and corresponding adjacent normal tissues were obtained from 139 GCA cases, which underwent surgical treatment in the Fourth Affiliated Hospital, Hebei Medical University and county hospital of high incidence regions between the years of 2004 and 2008. All gastric cardia carcinomas were adenocarcinomas with their epicenters at the gastroesophageal junction, i.e. from $1 \mathrm{~cm}$ above until $2 \mathrm{~cm}$ below the junction between the end of the tubular esophagus and the beginning of the saccular stomach [23]. All subjects were interviewed by professional interviewers for their age, gender, upper gastrointestinal cancers (UGIC) family history, and histopathological diagnosis. Individuals with at least one first-degree relative or at least two second-degree relatives having esophageal/cardia/ gastric cancer were defined as having family history of upper gastrointestinal cancers (UGIC). Information on clinicopathologic characteristics was obtained from pathological diagnosis and hospital recordings. Histological tumor typing of the cases was carried out on the basis of resected specimens in the department of pathology of the same hospital. Survival and recurrence data were available from the Tumor Registry and Hospital chart review.

Tumor tissues and corresponding normal tissues were divided into two parallel parts, one part was formalin-fixed and paraffin-embedded, and the other part was frozen and stored at $-80^{\circ} \mathrm{C}$ until DNA and RNA was extracted. The informed consent was obtained from all recruited subjects and the study was approved by the Ethics Committee of Hebei Cancer Institute.

FBXO32, Smad2, Smad3 and Smad4 mRNA expression via regular reverse transcription-polymerase chain reaction (RT-PCR) and quantitative real-time RT-PCR assays. Total RNA from frozen tumors and corresponding normal tissues was extracted with Trizol (Invitrogen, Carlsbad, CA, USA) according to the manufacturer's protocol. The quality and integrity of extracted RNA was quantified by UV absorbance at 260 to $280 \mathrm{~nm}$. After that, two $\mu \mathrm{g}$ RNA was used to synthesize cDNA by using the advantage RT-forPCR kit (Clontech, Palo Alto, CA, USA). cDNA from each sample was used as regular RT-PCR and qRT-PCR template and primers for FBXO32, Smad2, Smad3 and Smad4 were used as previously described $[16,22]$. All of the primers and reaction conditions were described in Supplementary table 1. The glyceraldehyde-3-phosphate dehydrogenase (GAPDH) gene was chosen as internal control. For regular RT-PCR, the PCR products were resolved on $2 \%$ agarose gels and quantified using Gel work-2ID system. The level of objective genes was determined by quantifying the intensities of the PCR product versus GAPDH. The reaction was repeated once with each of the samples for quality control. For quantitative real-time RT-PCR, power SYBR Green Master Mix (Applied Biosystems, Foster City, CA, USA) was used as amplification reaction mixture according to the manufacturer's instructions. The melting curve analysis was performed to confirm PCR product specificity. The expression levels of objective genes 
were normalized with GAPDH using the $2^{-\Delta \Delta C T}$ method [24]. All the samples were run in triplicate for quality control.

FBXO32, p-Smad2/3, and Smad4 protein expression via immunohistochemical staining. Immunohistochemical method was used to detect protein expression of FBXO32, $\mathrm{p}$-Smad2/3, and Smad4 on parallel histopathological sections from paraffin-embedded tumor and corresponding normal tissues. Briefly, after endogenous peroxidase was blocked with $3 \%$ hydrogen peroxide for 10 minutes, microwave antigen retrieval was done for nine minutes at $98^{\circ} \mathrm{C}$ in $10 \mathrm{mM}$ sodium citrate buffer $(\mathrm{pH} 6.0)$ and incubated in $2 \%$ normal horse serum to minimize non-specific binding. Then the primary antibody against FBXO32 (1:200 dilution, rabbit anti-human polyclonal antibody, Abcam, UK), p-Smad2/3 (Ser 423/425) (1:200 dilution, goat anti-human polyclonal antibody, Santa Cruz, San Diego, CA, USA), or Smad4 (1:200 dilution, mouse anti-human monoclonal antibody, Santa Cruz, San Diego, CA, USA) was applied to sections at room temperature overnight, which were then incubated with biotinylated secondary antibody and $\mathrm{ABC}$ reagent. 0.5\% 3, 3'-Diaminobenzidine (Sigma, St Louis, MO, USA) was used as the chromagen. Slides with positive staining of FBXO32, $\mathrm{p}$-Smad2/3, or Smad 4 in normal gastric mucosa were used as positive control. For a negative control, the primary antibody was replaced with mouse IgG.

Immunohistochemical staining was evaluated according to a scoring method reported previously [25]. Scoring accounted for both intensities of the stains and representation of the areas. Briefly, the score is the sum of the staining intensity ( 0 , negative; 1 , weak; 2 , moderate; 3 , strong) and percentage of positive cells ( 0 , less than $25 \%$ positive cells; $1,26 \%$ to $50 \%$ positive cells; $2,51 \%$ to $75 \%$ positive cells, and 3 , more than $75 \%$ positive cells). Sums between 0 and 2 were scored as negative; sums of 3 and 6 were scored as positive. All sections were examined and scored by three independent observers, who were blinded to the clinicopathologic features or clinical outcome.

DNA extraction and sodium bisulfite treatment. Genomic DNA from tumor and corresponding normal sections was first isolated from flash frozen tissues using a simplified Proteinase K digestion method. The isolated genomic DNA was then treated with sodium bisulfite as described previously to examine the DNA methylation patterns [19]. In brief, $2 \mu \mathrm{g}$ of DNA was denatured with $2 \mathrm{M} \mathrm{NaOH}$ at $37^{\circ} \mathrm{C}$ for $10 \mathrm{~min}$ utes, followed by incubation with $3 \mathrm{M}$ sodium bisulphate (pH5.0). The samples were then over layered with mineral oil and incubated at $50^{\circ} \mathrm{C}$ for 16 hours. The samples were then desalted through a column of Wizard DNA Clean-up System (Promega, Wisconsin, USA) according to the manufacturer's instructions. Finally, the treated samples were resuspended in $20 \mu \mathrm{l}$ of distilled water. After the standard sodium bisulfite DNA modification, methylated cytosine residues were retained as cytosine at $\mathrm{CpG}$ sites, while unmethylated cytosine residues were converted to thymine.

Methylation status of every CpG site of FBXO32 via bisulfite genomic sequencing (BGS) method. The methylation status of every CpG site in the FBXO32 CpG island 1 and 2 was then verified by BGS method in 5 matched tissue sets showing tumor-specific reduction of FBXO32 transcript levels. For BGS, primers were designed to recognize sodium bisulfite converted DNA and encompassing CpG island within the human FBXO32 gene promoter region (from -624 to -106bp). Fifty ng of bisulfite-modified DNA was subjected to PCR amplification and the PCR products were cloned into pGEM-T vectors (Promega, CA, USA) and 8 to 10 clones of each specimen were sequenced by automated fluorescencebased DNA sequencing.

FBXO32 methylation analysis via bisulfite conversionspecific and methylation-specific polymerase chain reaction (BS-MSP) method. The methylation status of FBXO32 was then determined by bisulfite conversion-specific and methylation-specific polymerase chain reaction method (BS-MSP) as described previously [26]. BS-MSP method consists of twostep PCR amplifications. In the first step of BS-MSP, $100 \mathrm{ng}$ of bisulfite-treated DNA was amplified and a primer set that does not contain any $\mathrm{CpG}$ but contains many cytosines of non-CpG sites at the 3 ' position was used. Only the sequence that is fully converted by bisulfite is amplified. Then the conventional MSP primer sets that contain many cytosines of CpG sites at the 3' position specific for methylated and unmethylated sequences were used in the second step of BS-MSP. BS-MSP method can efficiently eliminate unconverted DNA to avoid overestimation of the DNA methylation level in the samples. The promoter region (from -475 to $-288 \mathrm{bp}$ ) of FBXO32 gene was analyzed as previously reported [22]. The primers and reaction conditions were listed in Supplementary table 1. Blank water was used as a negative control and CpG methyltransferase (Sss I) (New England BioLabs, Beverly, MA, USA) treated genomic DNA was used as a positive control. BS-MSP products were analyzed on $2 \%$ agarose gel with ethidium bromide staining, and were determined to be methylated if a visible band was observed in the methylation reaction. Reactions were performed in duplicate with each of the samples, in order to ensure the consistency and reproducibility of the results.

Statistical analysis. The statistical analysis was performed using SPSS13.0 software package (SPSS Company, Chicago, Illinois, USA). Chi-square test was used to test the associations between FBXO32 methylation and FBXO32, p-Smad2/3, Smad4 protein expression and clinicopathological factors. Relationships between variables were tested by Spearman correlation analysis. The results of RT-PCR, and real-time RT-PCR were expressed as the mean \pm S.D. Student's $t$ test was used to compare mRNA expression level between different groups. Kaplan Meier survival curves were constructed and the significance of differences between survival rates was verified using the Log-rank or the Breslow tests. Multivariate Cox's regression models were used to adjust for potentially confounding variables (e.g., stage and UGIC family history) and to evaluate the prognostic significance of FBXO32 expression and methylation. Two-sided tests were used to determine significance and $\mathrm{P}$ values less than 0.05 were considered significant for all tests. 


\section{Results}

Clinicopathologic features. The GCA cases included 109 male and 30 female, age ranged from 39 75, mean age 58.4. Based on TNM stage and histological differentiation, 5 were stage I (3.6\%), 56 were stage II $(40.3 \%)$, 62 were stage III (44.6\%), and 16 were stage IV (11.5\%); $57(41.0 \%)$ of them were well differentiated, 51 (36.7\%) were moderate differentiation and 31 (22.3\%) were poor differentiated. According to the UGIC family history, 61 of 139 GCA patients were with positive UGIC family history. Other clinicopathologic characteristics of GCA cases such as depth of invasion, LN metastasis, and distant metastasis or recurrence were listed in Table 1. The patients were followed up for a minimum period of 1.5 years (range, 1.5 to 7 years), with a median follow-up of 5.5 years for survivors. They were clinically assessed for signs of metastatic recurrence. Seventeen patients were lost to follow up (Table 1).

mRNA and protein expression of FBXO32 in GCA. The mRNA and protein expression of FBXO32 was detected in 139 GCA tumor tissues and corresponding normal tissues. FBXO32 mRNA expression in GCA tumor tissues was significantly decreased compared to corresponding normal tissues $(\mathrm{P}<0.01)$ (Figure 1A, 1B). FBXO32 mRNA expression was associated with TNM stage, pathological differentiation, and distant metastasis or recurrence of tumor. FBXO32 protein expression was observed in the cytoplasm of tumor or normal cells (Figure 1C). FBXO32 protein expression in tumor tissues $(34.5 \%, 48 / 139)$ was significantly lower than that in normal tissues $(82.0 \%, 114 / 139)(\mathrm{P}<0.01)$ (Table 2). When stratified for clinicopathologic characteristics, FBXO32 protein expression was associated with TNM stage, pathological differentiation, depth of invasion, LN metastasis, and distant metastasis or recurrence $(\mathrm{P}<0.05)$. When stratified for UGIC family history, frequency of FBXO32 protein expression in GCA cases with positive UGIC family history was significantly lower than that in GCA cases with negative UGIC family history $(\mathrm{P}<0.05)$ (Table 3$)$.

mRNA and protein expression of R-Smad and Smad4 in GCA. The mRNA expression of Smad2 and Smad3 in GCA tumor tissues was significantly reduced compared to corresponding normal tissues $(\mathrm{P}<0.01)$ (Figure 1A, 1B). The mRNA expression of Smad2 and Smad3 was associated with TNM stage and pathological differentiation of tumor $(\mathrm{P}<0.05)$. The $\mathrm{p}-\mathrm{Smad} 2 / 3$ protein expression was observed in nucleus of tumor or normal cells (Figure 1C). Positive protein expression of $\mathrm{p}-\mathrm{Smad} 2 / 3$ in tumor tissues $(42.4 \%$, 59/139) was significantly lower than that in corresponding normal tissues $(94.2 \%, 131 / 139)(\mathrm{P}<0.01)$ (Table 2). When stratified for clinicopathologic characteristics, p-Smad $2 / 3$ protein expression was associated with TNM stage, pathological differentiation, and distant metastasis or recurrence $(\mathrm{P}<0.05)$ (Table 3).

Table 1. Clinicopathologic characteristics of gastric cardia adenocarcinoma cases

\begin{tabular}{|c|c|}
\hline Groups & $\mathrm{N}(\%)$ \\
\hline \multicolumn{2}{|l|}{ Age } \\
\hline$<50$ & $26(18.7)$ \\
\hline$\geq 50$ & $113(81.3)$ \\
\hline \multicolumn{2}{|l|}{ Gender } \\
\hline Male & $109(78.4)$ \\
\hline Female & $30(21.6)$ \\
\hline \multicolumn{2}{|l|}{ TNM stage } \\
\hline I & $5(3.6)$ \\
\hline II & $56(40.3)$ \\
\hline III & $62(44.6)$ \\
\hline IV & $16(11.5)$ \\
\hline \multicolumn{2}{|c|}{ Pathological differentiation of tumor } \\
\hline Well & $57(41.0)$ \\
\hline Moderate & $51(36.7)$ \\
\hline Poor & $31(22.3)$ \\
\hline \multicolumn{2}{|l|}{ Depth of invasion } \\
\hline $\mathrm{T} 1 / 2$ & $45(32.4)$ \\
\hline $\mathrm{T} 3 / 4$ & $94(67.6)$ \\
\hline \multicolumn{2}{|l|}{ LN metastasis } \\
\hline negative (N0) & $22(15.8)$ \\
\hline positive (N1/2/3) & $117(84.2)$ \\
\hline \multicolumn{2}{|c|}{ Distant metastasis or recurrence } \\
\hline negative & $70(50.4)$ \\
\hline positive & $69(49.6)$ \\
\hline \multicolumn{2}{|l|}{ Family history of UGIC } \\
\hline negative & $78(56.1)$ \\
\hline positive & $61(43.9)$ \\
\hline \multicolumn{2}{|l|}{ Vital statistics } \\
\hline Alive & $41(29.5)$ \\
\hline Dead GCA & $74(53.2)$ \\
\hline Dead unrelated & $7(5.1)$ \\
\hline Information unavailable & $17(12.2)$ \\
\hline
\end{tabular}

Table 2. Protein expression of FBXO32, p-Smad2/3 and Smad4 and methylation status of FBXO32 in GCA tumor tissues and corresponding normal tissues

\begin{tabular}{|c|c|c|c|c|c|c|c|c|c|}
\hline \multirow[t]{2}{*}{ Group } & \multirow[t]{2}{*}{$\mathrm{N}$} & \multicolumn{2}{|c|}{ FBXO32 protein expression } & \multicolumn{2}{|c|}{$\mathrm{p}-\mathrm{Smad} 2 / 3$ protein expression } & \multicolumn{2}{|c|}{ Smad4 protein expression } & \multicolumn{2}{|c|}{$\begin{array}{l}\text { FBXO32 methylation fre- } \\
\text { quency }\end{array}$} \\
\hline & & $\mathrm{n}(\%)$ & $\mathrm{P}$ & $\mathrm{n}(\%)$ & $\mathrm{P}$ & $\mathrm{n}(\%)$ & $\mathrm{P}$ & $\mathrm{n}(\%)$ & $\mathrm{P}$ \\
\hline Normal tissues & 139 & $114(82.0)$ & & $131(94.2)$ & & 133(95.7) & & $5(3.6)$ & \\
\hline Tumor tissues & 139 & $48(34.5)$ & $<0.001$ & $59(42.4)$ & $<0.001$ & $64(46.0)$ & $<0.001$ & $62(44.6)$ & $<0.001$ \\
\hline
\end{tabular}



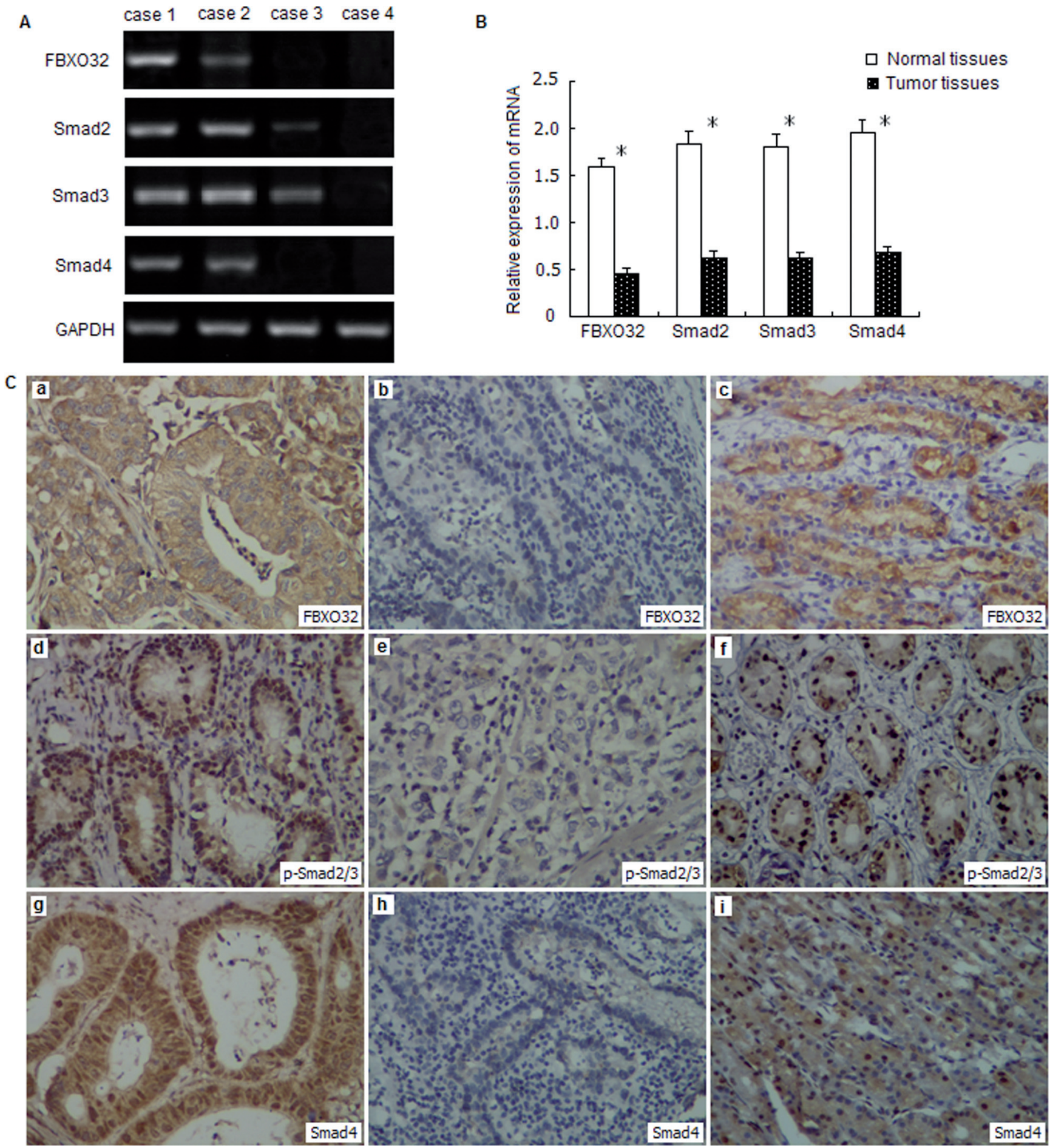

Figure 1. mRNA expression, and immunohistochemical staining of FBXO32, Smad2, Smad3 (p-Smad2/3), Smad4 in tissues.

A. RT-PCR analysis of FBXO32, Smad2, Smad3, and Smad4 in GCA tumor tissues. B. Relative mRNA expression of FBXO32, Smad2, Smad3, and Smad 4 in tumor tissues and corresponding normal tissues detected by quantitative real-time RT-PCR. ${ }^{\star} P<0.05$. C. Immunohistochemical staining of FBXO32, p-Smad2/3, and Smad4 in GCA tumor tissues and gastric normal tissues (SP $\times 400)$. a. positive staining of FBXO32 in GCA tumor tissue; $b$. negative staining of FBXO32 in GCA tumor tissue; c. positive staining of FBXO32 in normal tissue; d. positive staining of p-Smad2/3 in GCA tumor tissue; e. negative staining of $\mathrm{p}$-Smad2/3 in GCA tumor tissue; f. positive staining of p-Smad2/3 in normal tissue; g. positive staining of Smad4 in GCA tumor tissue; h. negative staining of Smad4 in GCA tumor tissue; i. positive staining of Smad4 in normal tissue. 
The mRNA expression of Smad4 in GCA tumor tissues was significantly reduced compared to corresponding normal tissues $(\mathrm{P}<0.01)$ (Figure 1A, 1B). The mRNA expression of Smad4 was associated with TNM stage of tumor $(\mathrm{P}<0.05)$. Smad4 protein expression was observed in nucleus and cytoplasm of tumor or normal cells (Figure 1C). Positive protein expression of Smad4 in tumor tissues $(46.0 \%, 64 / 139)$ was significantly lower than that in corresponding normal tissues $(95.7 \%, 133 / 139)(\mathrm{P}<0.01)$ (Table 2). When stratified for clinicopathologic characteristics, Smad4 protein expression was associated with TNM stage, depth of invasion, and distant metastasis or recurrence $(\mathrm{P}<0.05)$ (Table 3$)$.

Association of FBXO32 expression and p-Smad2/3, Smad4 expression. It has been reported that FBXO32 may act as a new TGF- $\beta /$ Smad signaling pathway target gene; we further investigate the association of FBXO32 expression and $\mathrm{p}-\mathrm{Smad} 2 / 3, \operatorname{Smad} 4$ expression. As shown in Table 4, of 48 GCA tumor tissues which showed positive expression of FBXO32, 40 GCA tumor tissues showed positive expression of $\mathrm{p}-\mathrm{Smad} 2 / 3$ and 42 GCA tumor tissues showed positive expression of Smad4. A positive close correlation was noted between FBXO32 and p-Smad2/3, Smad4 protein expression $(\mathrm{P}<0.05)(\mathrm{R}=0.601$ and 0.604 , respectively, $\mathrm{P}<0.01$ ).

Methylation analysis of FBXO32 in GCA. The MethPrimer program [27] and the CpG Island Searcher [28] were used to determine the $\mathrm{CpG}$ islands of FBXO32. As shown in Figure 2A, 2 CpG islands are found to be located in FBXO32 promoter and exon 1 . The methylation status of the $\mathrm{CpG}$ sites in $\mathrm{FBXO} 32$ promoter region was verified by BGS assay (Figure 2B). As shown in Figure 2B, 5 tumor tissues with low FBXO32 level showed frequent promoter hypermethylation of FBXO32, whereas methylation was very rare in the corresponding normal tissues. The methylation analysis of the promoter region (from -475 to $-288 \mathrm{bp}$ ) of FBXO32 was then successfully performed in all specimens (Figure 2C). The frequency of FBXO32 methylation in GCA tumor tissues $(44.6 \%, 62 / 139)$ was significantly higher than that in corresponding normal tissues $(3.6 \%, 5 / 139)(\mathrm{P}<0.05)$ (Table 2). FBXO32 methylation status in GCA tumor tissues was not associated with age and gender $(\mathrm{P}>0.05)$. When stratified for clinicopathologic characteristics, methylation frequency of FBXO32 was associated with TNM stage, pathological dif-

Table 3. Immunohistochemical staining characteristics of FBXO32, p-Smad2/3 and Smad4 and methylation status of FBXO32 in GCA tissues

\begin{tabular}{|c|c|c|c|c|c|c|c|c|c|}
\hline \multirow[t]{2}{*}{ Groups } & \multirow[t]{2}{*}{$\mathrm{N}$} & \multicolumn{2}{|c|}{$\begin{array}{l}\text { FBXO32 protein } \\
\text { expression }\end{array}$} & \multicolumn{2}{|c|}{$\begin{array}{c}\mathrm{p}-\mathrm{Smad} 2 / 3 \text { protein } \\
\text { expression }\end{array}$} & \multicolumn{2}{|c|}{$\begin{array}{c}\text { Smad4 protein } \\
\text { expression }\end{array}$} & \multicolumn{2}{|c|}{$\begin{array}{l}\text { FBXO32 methylation } \\
\text { frequency }\end{array}$} \\
\hline & & n (\%) & $\mathrm{P}$ & $\mathrm{n}(\%)$ & $\mathrm{P}$ & $\mathrm{n}(\%)$ & $\mathrm{P}$ & $\mathrm{n}(\%)$ & $\mathrm{P}$ \\
\hline \multicolumn{10}{|l|}{ Age } \\
\hline$<50$ & 26 & $8(30.8)$ & & $10(38.5)$ & & $11(42.3)$ & & $12(46.1)$ & \\
\hline$\geq 50$ & 113 & $40(35.4)$ & 0.654 & $49(43.3)$ & 0.648 & $53(46.9)$ & 0.672 & $50(44.2)$ & 0.860 \\
\hline \multicolumn{10}{|l|}{ Gender } \\
\hline Male & 109 & $37(33.9)$ & & $47(43.1)$ & & $50(45.8)$ & & $50(45.9)$ & \\
\hline Female & 30 & $11(36.7)$ & 0.781 & $12(40.0)$ & 0.760 & $14(46.7)$ & 0.938 & $12(40.0)$ & 0.567 \\
\hline \multicolumn{10}{|l|}{ TNM stage } \\
\hline I + II & 61 & $27(44.3)$ & & $32(52.4)$ & & $35(57.4)$ & & $20(32.8)$ & \\
\hline III + IV & 78 & $21(26.9)$ & 0.033 & $27(34.6)$ & 0.035 & $29(37.2)$ & 0.018 & $42(53.8)$ & 0.013 \\
\hline \multicolumn{10}{|c|}{$\begin{array}{l}\text { Pathological differentiation } \\
\text { of tumor }\end{array}$} \\
\hline Well/moderate & 108 & $42(38.9)$ & & $51(47.2)$ & & $53(49.1)$ & & $42(38.9)$ & \\
\hline Poor & 31 & $6(19.4)$ & 0.044 & $8(25.8)$ & 0.033 & $11(35.4)$ & 0.181 & $20(64.5)$ & 0.011 \\
\hline \multicolumn{10}{|l|}{ Depth of invasion } \\
\hline $\mathrm{T} 1 / 2$ & 45 & $21(46.7)$ & & $24(53.3)$ & & $27(60.0)$ & & $16(35.5)$ & \\
\hline $\mathrm{T} 3 / 4$ & 94 & $27(28.7)$ & 0.037 & $35(37.2)$ & 0.072 & $37(39.3)$ & 0.022 & $46(48.9)$ & 0.138 \\
\hline \multicolumn{10}{|l|}{ LN metastasis } \\
\hline negative (N0) & 22 & $12(54.5)$ & & $13(59.1)$ & & $13(59.1)$ & & $8(36.4)$ & \\
\hline positive $(\mathrm{N} 1 / 2 / 3)$ & 117 & $36(30.8)$ & 0.031 & $46(38.5)$ & 0.085 & $51(43.6)$ & 0.181 & $54(46.1)$ & 0.397 \\
\hline \multicolumn{10}{|l|}{$\begin{array}{l}\text { Distant metastasis or } \\
\text { recurrence }\end{array}$} \\
\hline negative & 70 & $30(42.8)$ & & $36(51.4)$ & & $39(55.7)$ & & $24(34.3)$ & \\
\hline positive & 69 & $18(26.1)$ & 0.038 & $23(33.3)$ & 0.031 & $25(36.2)$ & 0.021 & $38(55.1)$ & 0.014 \\
\hline \multicolumn{10}{|c|}{ Family history of UGIC } \\
\hline negative & 78 & $33(42.3)$ & & $37(47.4)$ & & $41(52.6)$ & & $28(35.9)$ & \\
\hline positive & 61 & $15(24.6)$ & 0.029 & $22(36.1)$ & 0.178 & $23(37.7)$ & 0.081 & $34(55.7)$ & 0.020 \\
\hline
\end{tabular}


ferentiation, and distant metastasis or recurrence $(\mathrm{P}<0.05)$ (Table 3). When stratified for UGIC family history, the methylation frequency of FBXO32 in GCA cases with positive UGIC family history was significantly higher than that in GCA patients with negative UGIC family history $(55.7 \%$ vs. $35.9 \%, \mathrm{P}<0.05$ ) (Table 3).

Association of FBXO32 methylation status and expression. FBXO32 mRNA expression in GCA tumor tissues with no detectable $\mathrm{FBXO} 32$ protein was significantly reduced compared to GCA tumor tissues with detectable FBXO32 protein $(\mathrm{P}<0.05)$. FBXO32 mRNA expression in GCA tumor tissues where promoter of FBXO32 was methylated was significantly reduced compared to that in GCA tumor tissues without methylation of the gene $(\mathrm{P}<0.05)$. The correlation of FBXO32 methylation and protein expression was shown in table 4, of 62 GCA tumor tissues which showed hypermethylation of FBXO32, 49 GCA tumor tissues showed negative protein expression of FBXO32, and the other 13 GCA tumor tissues which showed positive protein expression of FBXO32 all demonstrated incomplete methylation of this gene. A close

A

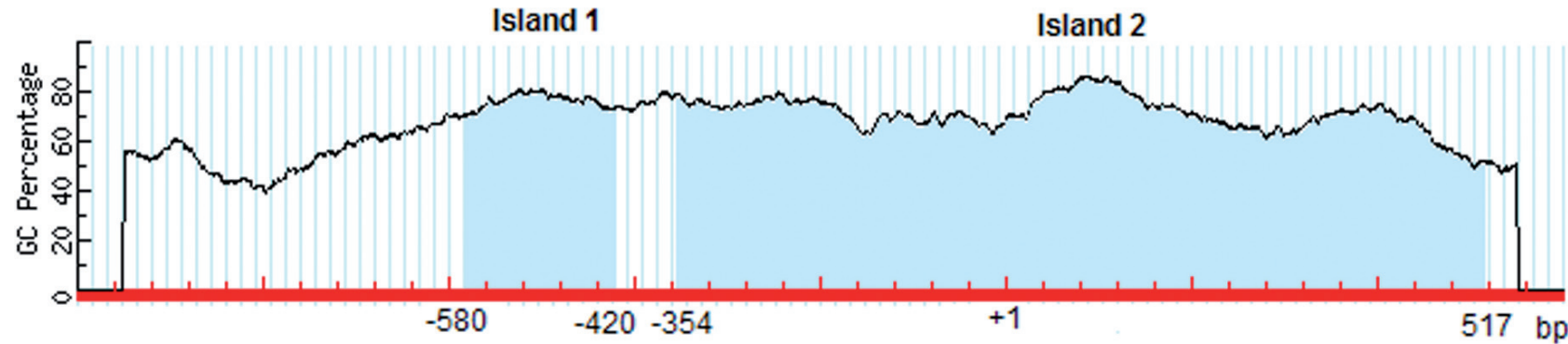

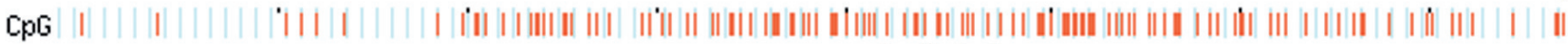<smiles>[3H]</smiles>

$\rightarrow \quad \leftarrow$ MSP

$\leftarrow$ first step

B
Cpg sites 1
10
20
30
40
50
P1|T $0000000 \bullet 000 \bullet 00 \bullet \bullet \bullet 0000000000 \bullet \bullet \bullet \bullet ० 0 \bullet \bullet 000 \bullet \bullet 00 \bullet 000000 \bullet$
I N 00000000000000000000000000000000000000000000000000
$\left.\mathrm{P} 2\right|_{\mathrm{N}} ^{\mathrm{T}} \mathrm{O} \mathrm{O} 00000000000000000 \bullet 00000000000 \bullet \bullet \bullet 00 \bullet 000 \bullet 0000000000 \bullet 000$
P3|T $0000000 \bullet 00 \bullet \bullet 0 \bullet \bullet \bullet \bullet 0000000000 \bullet \bullet \bullet \bullet \bullet 000 \bullet \bullet 00 \bullet 0000000 \bullet 00$
P3| T

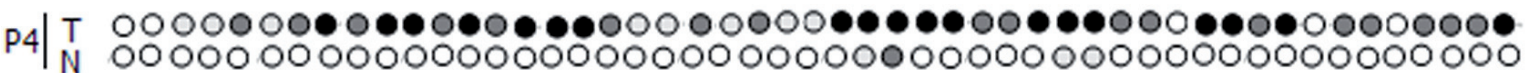
P5|T $00000000 \bullet 0 \bullet 00 \bullet 0 \bullet \bullet \bullet 000000 \bullet 0 \bullet \bullet \bullet \bullet ० 0 \bullet \bullet 0 \bullet \bullet \bullet \bullet \bullet 0000 \bullet 000 \bullet 0$
N 00000000000000000000000000000000000000000000000000 $-624$

\begin{tabular}{|cccc|}
\hline 0 & $\circ$ & 0 & $\bullet$ \\
$<10 \%$ & $10-40 \%$ & $40-70 \%$ & $>70 \%$ \\
\hline
\end{tabular}

C

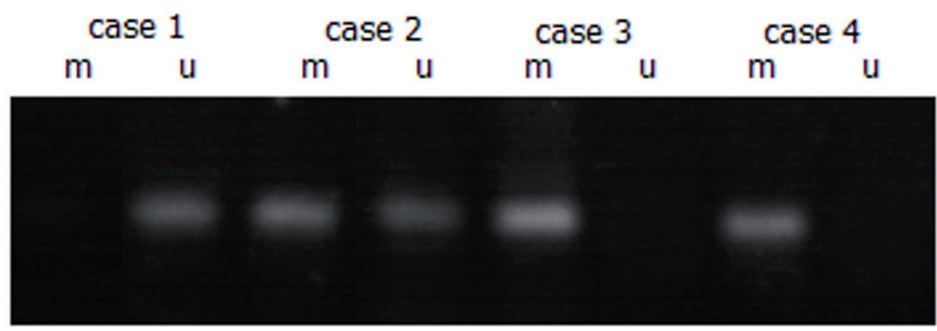

Figure 2. Schematic structure of the FBXO32 CpG island and methylation analysis of FBXO32 in GCA tumor tissues.

A. Two CpG islands are shown and the MSP region analyzed is indicated. B. The methylation status of every CpG site in the FBXO32 promoter region detected by BGS in 5 tumor tissues and corresponding normal tissues. Each CpG site is shown at the top row as an individual number. Percentage methylation was determined as percentage of methylated cytosines from 8 to 10 sequenced colonies. The color of circles for each CpG site represents the percentage of methylation. C. The methylation status of FBXO32 regulatory CpG sites determined by BS-MSP analysis in GCA tumor tissues. Case 1: FBXO32 is unmethylated; case 2: FBXO32 is semi-methylated; case 3 and case 4: FBXO32 is fully methylated; m: methylated; u: unmethylated. 
correlation was noted between FBXO32 promoter methylation and the loss of protein expression of the gene in GCA $(\mathrm{R}=-$ $0.256, \mathrm{P}<0.01$ ) (Table 4).

Survival analysis of FBXO32 methylation and expression in GCA. FBXO32 methylation was inversely correlated with GCA patient's survival (Figure 3A). In the FBXO32methylated GCA tumors, the 5-year overall survival rates (OS) were $15 \%$ (median survival time, 31 months; $\mathrm{P}<0.05$; Log-rank test) as opposed to the FBXO32-unmethylated GCA tumors displaying 5-year survival rates of 50\% (median survival time not reached). FBXO32 expression was positively correlated with GCA patients' survival (Figure 3B). In the FBXO32-expression GCA tumors, the 5-year survival rates were $55 \%$ (median survival time not reached) as opposed to the FBXO32-negative GCA tumors displaying 5-year survival rates of $16 \%$ (median survival time, 29 months; $\mathrm{P}<0.05$; Logrank test) (Supplementary table 2). The p-Smad $2 / 3$ and Smad 4 expression was also positively correlated with GCA patients' survival (Figure 3C, 3D). As shown in Figure 3E and 3F, GCA patients with both negative protein expression and methylation of FBXO32 showing poor patient survival. GCA patients with simultaneous negative protein expression of FBXO32, $\mathrm{p}$-Smad2/3, and Smad4 showed poor patient survival. GCA patients in stage III and IV, with positive UGIC family history, and hypermethylation or negative expression of FBXO32 were most likely to develop metastatic disease and also showed the worse survival.

Cox multivariate analysis was done using FBXO32 methylation, expression of FBXO32, p-Smad2/3, and Smad4, tumor stage, as well as other confounding variables such as UGIC family history, age, and patient gender. FBXO32 methylation status and protein expression, $\mathrm{p}-\mathrm{Smad} 2 / 3$ protein expression, TNM stage and UGIC family history were independently associated with GCA patients' survival (Table 5).

\section{Discussion}

The F-box protein functions as an adaptor that binds proteins to be ubiquitinated and, through the F-box, associates with the Skp1 protein (or a homolog) and thus with other components of the E3 complex [9]. FBXO32 contains a functional F-box domain that binds to Skp1 and thereby to Roc1 and Cull, the other components of SCF-type Ub-protein ligases (E3s), as well as a PDZ-binding domain and nuclear localization sequence. Recent findings have demonstrated that two other members of F-Box protein FBXW7 and FBX4 can function as tumor suppressors $[29,30]$, and following studies thus far have linked FBXO32 with cancer. Frolov et al. showed that FBXO32 was up-regulated in gastrointestinal stromal tumor after treatment with Gleevec and that its expression was regulated by ERK 1/2-dependent pathway [31]. Recent findings suggest that FBXO32 is a novel apoptosis regulator and is negatively regulated by a pro-survival signal $[10,11]$. More recently, FBXO32 was identified as a TGF- $\beta /$ Smad target gene and was found to be transcriptionally silenced by aberrant DNA hypermethylation in breast cancer cells and ovarian cancer cell lines $[11,12,22]$. Furthermore, the methylation status of FBXO32 may predict survival of ovarian cancer patients [22]. Only two studies concerned the role of FBXO32 in gastric cancer. Lei et al. found that SerpinB5 interacts with FBXO32 and KHDRBS3, and KHDRBS3 can interact with FBXO32 mRNA in gastric cancer [32]. D'Orlando et al. evaluated the gene expression levels of FBXO32 in skeletal muscle samples of patients with gastric cancer, and found the gene expression of FBXO32 in skeletal muscle is not affected by the presence of cancer [33]. However, the effect of FBXO32 in GCA has not been previously reported. As an adenocarcinoma of gastrointestinal epithelia, mechanisms of the occurrence and development of gastric cardia adenocarcinoma in North China remains unclear for the moment. Similar to the stud-

Table 4. The association of FBXO32 protein expression and methylation status, protein expression of p-Smad2/3, Smad4 in GCA cases

\begin{tabular}{ccccccc}
\hline \multirow{2}{*}{ FBXO32 protein expression } & \multicolumn{2}{c}{ FBXO32 methylation } & \multicolumn{2}{c}{ p-Smad2/3 expression } & \multicolumn{2}{c}{ Smad4 expression } \\
\cline { 2 - 6 } & M U & P & +- & P & +- & 426 \\
\hline+ & 1335 & & 408 & & \\
-- & 4942 & 0.003 & 1972 & $<0.001$ & 2269 & $<0.001$ \\
\hline
\end{tabular}

M: methylated; U: unmethylated

Table 5. Multivariate analysis of survival in GCA cases (Cox's test)

\begin{tabular}{lcccc}
\hline Variable & $\mathrm{B}$ & $\mathrm{SE}$ & $\mathrm{P}$ & Odds ratio $(95 \% \mathrm{CI})$ \\
\hline FBXO32 expression & 0.930 & 0.370 & 0.012 & $2.535(1.227-5.236)$ \\
FBXO32 methylation & 0.562 & 0.233 & 0.016 & $1.755(1.111-2.773)$ \\
p-Smad2/3 expression & 0.608 & 0.287 & 0.034 & $1.837(1.047-3.224)$ \\
Smad4 expression & 0.305 & 0.310 & 0.325 & $1.357(0.739-2.492)$ \\
TNM stage & 1.682 & 0.274 & $<0.001$ & $5.374(3.143-9.188)$ \\
Family history of UGIC & 0.502 & 0.228 & 0.028 & $1.652(1.057-2.584)$ \\
\hline
\end{tabular}



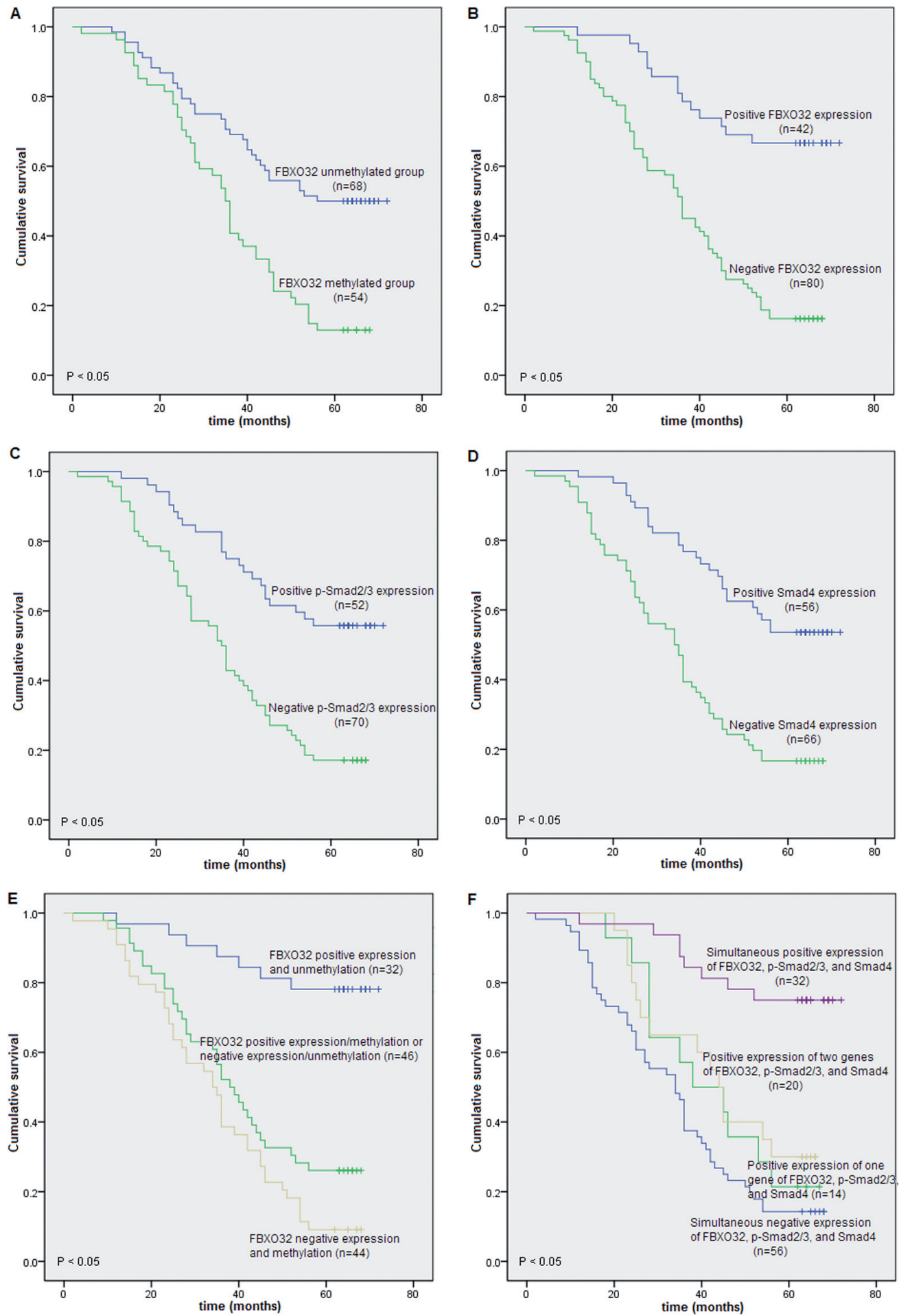

Figure 3. Kaplan-Meier univariate survival analysis of FBXO32, p-Smad2/3, and Smad4 expression in GCA.

A. Kaplan-Meier curves for cumulative survival stratified by FBXO32 methylation status: showing consistently a direct correlation between FBXO32 methylation and poor patient survival. B. Kaplan-Meier curves for cumulative survival stratified by FBXO32 expression status: showing a direct correlation between negative FBXO32 expression and poor patient survival. C. Kaplan-Meier curves for cumulative survival stratified by p-Smad2/3 expression status: showing a direct correlation between negative $\mathrm{p}-S \operatorname{mad} 2 / 3$ expression and poor patient survival. $D$. Kaplan-Meier curves for cumulative survival stratified by Smad 4 expression status: showing a direct correlation between negative Smad4 expression and poor patient survival. E. Kaplan-Meier curves for cumulative survival stratified by FBXO32 methylation status and expression: GCA patients with both negative protein expression and methylation of FBXO32 showing poor patient survival. F. Kaplan-Meier curves for cumulative survival stratified by FBXO32, p-Smad2/3, and Smad4 expression: GCA patients with simultaneous negative expression of FBXO32, p-Smad2/3, and Smad4 showing poor patient survival. 
ies of FBXO32 in breast cancer [11], and ovarian cancer [22], decreased expression of FBXO32 was also found in the present study, indicating the tumor suppressor gene role of FBXO32 in different tumors. In the present study, we also found aberrant hypermethylation of FBXO32 may be one of the mechanisms that lead to loss or down expression of the gene in GCA. The relatively larger samples and the reproductive methylation frequency suggested that the results in the present study may not elucidate the problem.

Our previous study has demonstrated that dysregulation and epigenetic inactivation of the key genes of TGF- $\beta$ / Smad signaling pathway may play crucial roles in GCA carcinogenesis [16]. It has been demonstrated that disruption of an upstream signaling pathway regulator may result in transcriptional repression of the downstream target genes through epigenetic mechanisms [34, 35]. Recently, Chan et al. [34] and Yeh et al. [36] have respectively verified that dysregulation of TGF- $\beta / \mathrm{Smad} 4$ signaling lead to epigenetic silencing of ADAM19 and RunX1T1, the downstream target genes in ovarian cancer cells, and meanwhile with impaired SMAD4 nuclear translocation. As a new target gene of TGF- $\beta /$ Smad signal pathway, epigenetic inactivation of FBXO32 has been found in ovarian cancer and aberrant DNA methylation of FBXO32 was further verified to be caused by dysregulation of TGF- $\beta /$ Smad 4 signaling in ovarian cancer $[12,22]$. Our investigation of FBXO32 in GCA further supports this theory. Decreased expression of $\mathrm{p}-\mathrm{Smad} 2 / 3, \mathrm{Smad} 4$, and FBXO32, and positive correlation between FBXO32 and p-Smad2/3, Smad4 expression were found in GCA tissues. Interestingly, protein expression of Smad 4 was found in both the cytoplasm and nucleus, mainly in nucleus in normal tissues; while mainly in cytoplasm in tumor tissues, indicating the blocking of Smad4 nuclear translocation in GCA. It has been well accepted that nuclear proteins are synthesized in the cytoplasm and need to be imported through the nuclear pore complexes into the nucleus. As a key gene of TGF- $\beta$ / Smad pathway, nuclear translocation effect of Smad4 may play crucial role in regulating target gene expression [22]. Our results suggest that dysregulation of the TGF- $\beta /$ Smad signaling pathway may contribute to FBXO32 methylation in GCA. Further investigations are needed to clarify the molecules and exact mechanisms which regulate the nuclear/cytoplasmic distribution of Smad4.

Chou et al. [22] found that ovarian cancer patients with high FBXO32 methylation had significantly shorter progressionfree survival than patients with low FBXO32 methylation, indicating that FBXO32 methylation may serve as a prognostic indicator. In the present study, hypermethylation and expression of FBXO32, expression of p-Smad2/3 and Smad4 were found to be significantly and directly correlated with GCA patients' survival. In multivariate analysis, the combination of tumor stage, FBXO32 methylation and expression was found to be independent predictive factor. Patients with decreased expression and hypermethylation of FBXO32, with positive UGIC family history, and in stage III and IV had the worst 5-year overall survival time. Thus, FBXO32 may be considered to be a new useful marker in predicting progression and prognosis of GCA.

In the high incidence region of North China, the exact reason for the development of GCA still remains unclear. Sufficient evidence supported that the occurrence of GCA was associated with UGIC family history, indicating the important roles of genetic background in the pathogenesis of GCA [19-21]. The association of family history and aberrant methylation of cancer-related genes also remains somewhat unclear. The findings of higher methylation frequency of FBXO32 in GCA patients with positive UGIC family history in the present study indicated that tumor suppressor genes may be more prone to be methylated in patients with positive UGIC family history. Further investigations are needed to be done to verify this hypothesis. In the present study, positive UGIC family history was also found to predict poor prognosis of GCA, and this findings further reinforced the importance of cancer prevention in the high incidence regions.

In all, our study suggest that FBXO32 is downregulated in GCA with impaired TGF- $\beta /$ Smad signaling, and promoter hypermethylation may be one of the mechanisms for inactivation of FBXO32 in GCA, especially in GCA patients with UGIC family history of North China. Additionally, decrease expression and hypermethylation of FBXO32, with positive UGIC family history, and in stage III and IV is highly predictive of metastasis and poor prognosis in GCA. Further studies need to be done to determine if FBXO32 can be used as a target to improve clinical outcome of GCA.

Supplementary information is available in the online version of the paper.

Acknowledgements: We thank the patients and control individuals for taking part in this study. Supported by Grants from the National Natural Science Foundation (No. 81101854).

\section{References}

[1] CREW KD, NEUGUT AI. Epidemiology of upper gastrointestinal malignancies. Semin Oncol 2004; 31:450-464. http:// dx.doi.org/10.1053/j.seminoncol.2004.04.021

[2] YANG L. Incidence and mortality of gastric cancer in China. World J Gastroenterol 2006; 12: 17-20.

[3] MA JL, ZHANG L, BROWN LM, LI JY, SHEN L et al. Fifteen-year effects of Helicobacter pylori, garlic, and vitamin treatments on gastric cancer incidence and mortality. J Natl Cancer Inst 2012; 104: 488-492. http://dx.doi.org/10.1093/ jnci/djs003

[4] GAO Y, HU N, HAN X, GIFFEN C, DING T et al. Family history of cancer and risk for esophageal and gastric cancer in Shanxi, China. BMC Cancer 2009; 9: 269. http://dx.doi. org/10.1186/1471-2407-9-269

[5] YANG CS. Vitamin nutrition and gastroesophageal cancer. J Nutr 2000; 130: 338S-339S. 
[6] YOKOKAWA Y, OHTA S, HOU J, ZHANG XL, LI SS et al. Ecological study on the risks of esophageal cancer in $\mathrm{Ci}$ Xian, China: the importance of nutritional status and the use of well water. Int J Cancer 1999; 83: 620-624. http://dx.doi. org/10.1002/(SICI) 1097-0215(19991126)83:5<620::AIDIJC9>3.0.CO; $2-\mathrm{W}$

[7] HANAI J, CAO P, TANKSALE P, IMAMURA S, KOSHIMIZU $\mathrm{E}$ et al. The muscle-specific ubiquitin ligase atrogin-1/MAFbx mediates statin-induced muscle toxicity. J Clin Invest 2007; 117: 3940-3951. http://dx.doi.org/10.1172/JCI32741

[8] LI HH, KEDAR V, ZHANG C, MCDONOUGH H, ARYA R et al. Atrogin-1/muscle atrophy F-box inhibits calcineurindependent cardiac hypertrophy by participating in an SCF ubiquitin ligase complex. J Clin Invest 2004; 114: 1058-1071. http://dx.doi.org/10.1172/JCI200422220

[9] GOMES MD, LECKER SH, JAGOE RT, NAVON A, GOLDBERG AL. Atrogin-1, a muscle-specific F-box protein highly expressed during muscle atrophy. Proc Natl Acad Sci U S A 2001; 98: 14440-14445. http://dx.doi.org/10.1073/ pnas. 251541198

[10] STITT TN, DRUJAN D, CLARKE BA, PANARO F, TIMOFEYVA Y et al. The IGF-1/PI3K/Akt pathway prevents expression of muscle atrophy-induced ubiquitin ligases by inhibiting FOXO transcription factors. Mol Cell 2004; 14: 395-403. http://dx.doi.org/10.1016/S1097-2765(04)00211-4

[11] TAN J, YANG X, ZHUANG L, JIANG X, CHEN W et al. Pharmacologic disruption of Polycomb-repressive complex 2 -mediated gene repression selectively induces apoptosis in cancer cells. Genes Dev 2007; 21: 1050-1063. http://dx.doi. org/10.1101/gad.1524107

[12] QIN H, CHAN MW, LIYANARACHCHI S, BALCH C, POTTER D et al. An integrative ChIP-chip and gene expression profiling to model SMAD regulatory modules. BMC Syst Biol 2009; 3: 73. http://dx.doi.org/10.1186/1752-0509-3-73

[13] ATTISANO L, WRANA JL. Signal transduction by the TGF- $\beta$ superfamily. Science 2002; 296: 1646-1647. http://dx.doi. org/10.1126/science.1071809

[14] SHI Y, MASSAGUE J. Mechanisms of TGF-beta signaling from cell membrane to the nucleus. Cell 2003; 113: 685-700. http://dx.doi.org/10.1016/S0092-8674(03)00432-X

[15] DERYNCK R, AKHURST RJ, BALMAIN A. TGF-beta signaling in tumor suppression and cancer progression. Nat Genet 2001; 29: 117-129. http://dx.doi.org/10.1038/ng1001-117

[16] GUO W, DONG Z, GUO Y, KUANG G, YANG Z et al. Concordant repression and aberrant methylation of transforming growth factor-beta signaling pathway genes occurs early in gastric cardia adenocarcinoma. Mol Biol Rep 2012; 39: 9453-9462. http://dx.doi.org/10.1007/s11033-012-1810-x

[17] BIRD A. Molecular biology. Methylation talk between histones and DNA. Science 2001; 294: 2113-2115. http://dx.doi. org/10.1126/science.1066726

[18] JONES PA, BAYLIN SB. The epigenomics of cancer. Cell 2007; 128: 683-692. http://dx.doi.org/10.1016/j.cell.2007.01.029

[19] GUO W, DONG Z, CHEN Z, YANG Z, WEN D et al. Aberrant CpG Island hypermethylation of RASSF1A in gastric cardia adenocarcinoma. Cancer Invest 2009; 27: 459-465. http:// dx.doi.org/10.1080/07357900802620828
[20] GUO W, DONG Z, GUO Y, CHEN Z, KUANG G et al. Aberrant methylation of the CpG island of HLTF gene in gastric cardia adenocarcinoma and dysplasia. Clin Biochem 2011; 44: 784-788. http://dx.doi.org/10.1016/j. clinbiochem.2011.04.006

[21] GUO W, DONG Z, GUO Y, LIN X, CHEN Z et al. Aberrant methylation and loss expression of RKIP is associated with tumor progression and poor prognosis in gastric cardia adenocarcinoma. Clin Exp Metastasis 2013; 30: 265-275. http:// dx.doi.org/10.1007/s10585-012-9533-X

[22] CHOU JL, SU HY, CHEN LY, LIAO YP, HARTMAN-FREY $\mathrm{C}$ et al. Promoter hypermethylation of FBXO32, a novel TGF- $\beta /$ SMAD 4 target gene and tumor suppressor, is associated with poor prognosis in human ovarian cancer. Lab Invest 2010; 90: 414-425. http://dx.doi.org/10.1038/ labinvest.2009.138

[23] SIEWERT JR, STEIN HJ. Classification of adenocarcinoma of the oesophagogastric junction. Br J Surg 1998; 85: 1457-1459. http://dx.doi.org/10.1046/j.1365-2168.1998.00940.x

[24] LIVAK KJ, SCHMITTGEN TD. Analysis of relative gene expression data using real-time quantitative PCR and the 2(-Delta Delta C(T)) method. Methods 2001; 25: 402-408. http://dx.doi.org/10.1006/meth.2001.1262

[25] UMEMOTO M, YOKOYAMA Y, SATO S, TSUCHIDA S, AL-MULLA F et al. Carbonyl reductase as a significant predictor of survival and lymph node metastasis in epithelial ovarian cancer. Br J Cancer 2001; 85: 1032-1036. http://dx.doi. org/10.1054/bjoc.2001.2034

[26] SASAKI M, ANAST J, BASSETT W, KAWAKAMI T, SAKURAGI $\mathrm{N}$ et al. Bisulfite conversion-specific and methylation-specific PCR: a sensitive technique for accurate evaluation of $\mathrm{CpG}$ methylation. Biochem Biophys Res Commun 2003; 309: 305-309. http://dx.doi.org/10.1016/j. bbrc.2003.08.005

[27] LI LC, DAHIYA R. MethPrimer: designing primers for methylation PCRs. Bioinformatics 2002; 18: 1427-1431. http:// dx.doi.org/10.1093/bioinformatics/18.11.1427

[28] TAKAI D, JONES PA. The CpG island searcher: a new WWW resource. In Silico Biol 2003; 3: 235-240.

[29] LIN DI, BARBASH O, KUMAR KG, WEBER JD, HARPER JW et al. Phosphorylation-dependent ubiquitination of cyclin D1 by the SCF(FBX4-alphaB crystallin) complex. Mol Cell 2006; 24: 355-366. http://dx.doi.org/10.1016/j.molcel.2006.09.007

[30] FUII Y, YADA M, NISHIYAMA M, KAMURA T, TAKAHASHI $\mathrm{H}$ et al. Fbxw7 contributes to tumor suppression by targeting multiple proteins for ubiquitin-dependent degradation. Cancer Sci 2006; 97: 729-736. http://dx.doi. org/10.1111/j.1349-7006.2006.00239.x

[31] FROLOV A, CHAHWAN S, OCHS M, ARNOLETTI JP, PAN $\mathrm{ZZ}$ et al. Response markers and the molecular mechanisms of action of Gleevec in gastrointestinal stromal tumors. Mol Cancer Ther 2003; 2: 699-709.

[32] LEI KF, LIU BY, WANG YF, CHEN XH, YU BQ et al. SerpinB5 interacts with KHDRBS3 and FBXO32 in gastric cancer cells. Oncol Rep 2011; 26: 1115-1120.

[33] D`ORLANDO C, MARZETTIE, FRANÇOIS S, LORENZI M, CONTI $V$ et al. Gastric cancer does not affect the expression of 
atrophy-related genes in human skeletal muscle. Muscle Nerve 2014; 49: 528-533. http://dx.doi.org/10.1002/mus.23945

[34] CHAN MW, HUANG YW, HARTMAN-FREY C, KUO CT, DEATHERAGE D et al. Aberrant transforming growth factor beta1 signaling and SMAD4 nuclear translocation confer epigenetic repression of ADAM19 in ovarian cancer. Neoplasia 2008; 10: 908-919.

[35] BAGNYUKOVA TV, TRYNDYAK VP, MUSKHELISHVILI L, ROSS SA, BELAND FA et al. Epigenetic downregulation of the suppressor of cytokine signaling 1 (Socs1) gene is associated with the STAT3 activation and development of hepatocellular carcinoma induced by methyl-deficiency in rats. Cell Cycle 2008; 7: 3202-3210. http://dx.doi.org/10.4161/cc.7.20.6816

[36] YEH KT, CHEN TH, YANG HW, CHOU JL, CHEN LY et al. Aberrant TGF $\beta / S M A D 4$ signaling contributes to epigenetic silencing of a putative tumor suppressor, RunX1T1 in ovarian cancer. Epigenetics 2011; 6: 727-739. http://dx.doi. org/10.4161/epi.6.6.15856 


\section{Supplementary Information}

\section{FBXO32, a new TGF- $\beta$ /Smad signaling pathway target gene, is epigenetically inactivated in gastric cardia adenocarcinoma}

W. GUO, M. ZHANG, Y. GUO, S. SHEN, X. GUO, Z. DONG*

Laboratory of Pathology, Hebei Cancer Institute, the Fourth Hospital of Hebei Medical University, Shijiazhuang, Hebei, China

*Correspondence: dongzhiming2000@163.com

\section{Supplementary table}

Table 1. Primer sequences and reaction conditions of FBXO32 used in this study

\begin{tabular}{|c|c|c|c|c|}
\hline PCR types & Gene & Primers & Annealing temperature $\left({ }^{\circ} \mathrm{C}\right)$ & Product size $(\mathrm{bp})$ \\
\hline \multirow[t]{10}{*}{ RT-PCR } & FBXO32 & F:5'-AAGTCTGTGCTGGTCGGGAA-3’ & & \\
\hline & & R:5'-AGTGAAGGTGAGGCCTTTGAAG-3' & 57 & 123 \\
\hline & Smad2 & F: 5'-GTTCCTGCCTTTGCTGAGAC-3' & & \\
\hline & & R: 5'-TCTCTTTGCCAGGAATGCTT-3' & 55 & 220 \\
\hline & Smad3 & F: 5'-TGCTGGTGACTGGATAGCAG-3' & & \\
\hline & & R: 5'-CTCCTTGGAAGGTGCTGAAG-3' & 56 & 176 \\
\hline & Smad4 & F: 5’-ATCTGAGTCTAATGCTACC-3’ & & \\
\hline & & R: 5'-CGTATCCATCAACAGTAAC-3' & 58 & 452 \\
\hline & GAPDH & F:5’-GGGAAACTGTGGCGTGAT-3’' & & \\
\hline & & R:5'-GTGGTCGTTGAGGGCAAT-3’' & & 342 \\
\hline \multirow[t]{2}{*}{ BGS } & & F:5'-TTGGTTAGTGATAGTTAAGG-3' & & \\
\hline & & R:5'-TAACTTTATTTATAAACT-3' & 54 & 519 \\
\hline \multirow[t]{7}{*}{ BS-MSP } & First-step & F:5'-TTGGTTAGTGATAGTTAAGG-3' & & \\
\hline & & R:5'-TAACTTTATTTATAAACT-3' & 54 & 519 \\
\hline & Second-step & & & \\
\hline & Methylation & F:5'-TTAGTTTTGCGGACGGTTCGGGAGG-3' & & \\
\hline & & R:5'-ACGCTTAAAAAAATACGCCCCGATC-3' & 55 & 188 \\
\hline & Unmethylation & F:5'-TTAGTTTTGTGGATGGTTTGGGAGG-3' & & \\
\hline & & R:5'-ACACTTAAAAAAATACACCCСAATC-3' & 55 & 188 \\
\hline
\end{tabular}


Table 2. Univariate analysis of survival in GCA cases (log-rank test)

\begin{tabular}{|c|c|c|}
\hline \multirow{2}{*}{ Groups } & \multicolumn{2}{|c|}{ Univariate } \\
\hline & 5 -yr OS & $\mathrm{P}$ \\
\hline \multicolumn{3}{|l|}{ Age } \\
\hline$<50$ & 20 & \\
\hline$\geq 50$ & 38 & 0.235 \\
\hline \multicolumn{3}{|l|}{ Gender } \\
\hline Male & 32 & \\
\hline Female & 35 & 0.421 \\
\hline \multicolumn{3}{|l|}{ TNM stage } \\
\hline I + II & 49 & \\
\hline III + IV & 21 & 0.001 \\
\hline \multicolumn{3}{|c|}{ Pathological differentiation of tumor } \\
\hline Well/moderate & 37 & \\
\hline Poor & 22 & 0.269 \\
\hline \multicolumn{3}{|l|}{ Depth of invasion } \\
\hline $\mathrm{T} 1 / 2$ & 45 & \\
\hline $\mathrm{T} 3 / 4$ & 28 & 0.009 \\
\hline \multicolumn{3}{|l|}{ LN metastasis } \\
\hline negative (N0) & 65 & \\
\hline positive $(\mathrm{N} 1 / 2 / 3)$ & 29 & 0.001 \\
\hline \multicolumn{3}{|c|}{ Distant metastasis or recurrence } \\
\hline negative & 45 & \\
\hline positive & 22 & 0.001 \\
\hline \multicolumn{3}{|l|}{ Family history of UGIC } \\
\hline negative & 41 & \\
\hline positive & 25 & 0.009 \\
\hline \multicolumn{3}{|c|}{ FBXO32 methylation status } \\
\hline methylation & 15 & \\
\hline unmethylation & 50 & $<0.001$ \\
\hline \multicolumn{3}{|c|}{ FBXO32 protein expression } \\
\hline positive & 55 & \\
\hline negative & 16 & $<0.001$ \\
\hline \multicolumn{3}{|c|}{$\mathrm{p}$-Smad $2 / 3$ protein expression } \\
\hline positive & 54 & \\
\hline negative & 18 & $<0.001$ \\
\hline \multicolumn{3}{|c|}{ Smad4 protein expression } \\
\hline positive & 52 & \\
\hline negative & 20 & $<0.001$ \\
\hline
\end{tabular}

